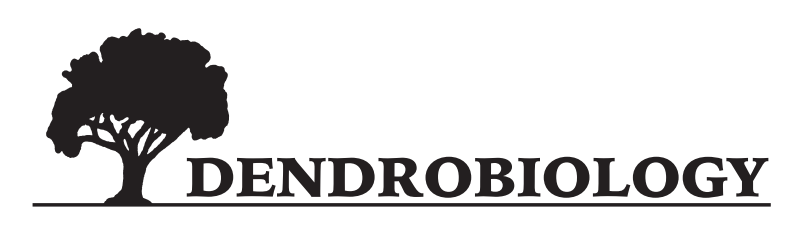

2015, vol. 74, 149-155

http://dx.doi.org/10.12657/denbio.074.015

\author{
Elias Pipinis, Olga Mavrokordopoulou, Elias Milios, \\ Apostolina Diamanta, Ioanna Kotili, Pavlos Smiris
}

\title{
Effects of dormancy-breaking treatments on seed germination of Koelreuteria paniculata and Mahonia aquifolium
}

Received: 14 December 2014; Accepted: 12 May 2015

\begin{abstract}
The present paper examines the germination requirements of the seeds of two woody species (Koelreuteria paniculata and Mahonia aquifolium). Koelreuteria paniculata seeds were subjected to a combination of acid scarification, gibberellic acid $\left(\mathrm{GA}_{3}\right)$ and cold stratification treatments. Un-scarified seeds, which were only cold stratified (up to 3 months) as well as the seeds which were only acid-scarified (up to 60 minutes) exhibited low germination percentages. The combination of sulphuric acid scarification and cold stratification treatments significantly improved germination. In acid-scarified seeds, GA application improved germination, but did not fully replace the cold stratification period required to break seed dormancy. Mahonia aquifolium seeds were subjected to a combination of $\mathrm{GA}_{3}$ and cold stratification treatments. Notably, prolonged cold stratification is essential for the germination of $M$. aquifolium seeds since seeds stratified for 1 or even 2 months did not germinate. In almost all cases, the percentage of $M$. aquifolium seeds germinated was higher with $\mathrm{GA}_{3}$ treatment applied prior to cold stratification than with cold stratification only.

Additional key words: Cold stratification, Gibberellic acid, Sulphuric acid, Scarification

Addresses: E. Pipinis, O. Mavrokordopoulou, A. Diamanta, I. Kotili, P. Smiris, Laboratory of Silviculture, Department of Forestry and Natural Environment, Aristotle University of Thessaloniki, 54124 Thessaloniki, Greece, e-mail: epipinis@for.auth.gr

E. Milios, Department of Forestry and Management of the Environment and Natural Resources, Democritus University of Thrace, Pandazidou 193, 68200 Orestiada, Greece
\end{abstract}

\section{Introduction}

Koelreuteria paniculata Laxm., which is a small deciduous tree native to China, Korea and Japan (Michler and Rudolf 2008), is ornamental, mainly planted in gardens, as its yellow flowers and green leaves are aesthetically appealing (Rehman and Park 2000). Mahonia aquifolium (Pursh) Nutt. is an evergreen shrub, native to western North America, which was introduced in Europe as an ornamental species due to its leaves, yellow flowers and blue berries (Kowarik 1992). In addition, M. aquifolium is a valued medicinal plant as it is a rich source of phenolics and antioxidants (Gunduz 2013).

The aforementioned species can be propagated with seeds in nurseries, as the specific method is cost-effective (Mcdonald 2006). However, a major constraint to the sexual propagation of many species 
is the poor germination of their seeds. This is possibly due to low viability, although it is frequently due to seed dormancy (Mackay et al. 2002), which is a physiological state, during which a viable seed fails to germinate even when the environment is favorable to germination (Mcdonald 2006). The causes of seed dormancy can be attributed to exogenous (seed coat and other structures prevent germination), or endogenous factors (embryo characteristics that prevent germination) and also a combination of both (Nikolaeva 1977). According to Rehman and Park (2000), the reasons of dormancy of $K$. paniculata seeds are found in seed coats and embryos. Furthermore, Michler and Rudolf (2008) state that dormancy is caused by the impermeability of seed coats and possibly by embryos. The presence of a hard, impermeable seed coat (physical dormancy) and embryo (physiological) dormancy in a single seed is called combinational dormancy (Baskin and Baskin 2004). As far as M. aquifolium is concerned, in the relevant literature the type of seed dormancy has not been accurately determined. Seeds of some species of $\mathrm{Ma}$ honia genus exhibit physiological dormancy, whereas an immature or improperly developed embryo is possibly present in seeds of other species (Dirr and Heuser 1987; Baskin et al. 1993).

Various methods are used to overcome different types of dormancy, so that the highest percentage of viable seeds could be brought to the point of germination. Scarification (mechanical or acid) treatment is used to soften the seed coat making seeds permeable to water (Baskin and Baskin 1998), whereas cold moist stratification is widely used for breaking embryo dormancy and enhancing the germination of seeds in numerous species (Macdonald 2006). In case of $K$. paniculata, there are contradictory results regarding the effectiveness of the scarification treatment in dormancy-breaking and germination of seeds. Stilinovic and Grbic (1988) stated that a single mechanical scarification treatment for breaking seed coat dormancy improves the K. paniculata seed germination. Furthermore, Dirr and Heuser (1987) stated that if seed coat becomes permeable, some seeds will germinate. In contrast, Rehman and Park (2000) stated that the germination of $K$. paniculata seeds is not induced by a single manual scarification treatment. Thus, the assumption that scarification treatment overcomes dormancy and improves the germination of $K$. paniculata seeds incurs the risk of poor germination. Seed scarification followed by cold stratification is suggested as the best treatment to break dormancy in seeds with combinational dormancy (Baskin and Baskin 1998). For the best results in germination of $K$. paniculata seeds, Rudolf (1974b) recommends scarification with sulphuric acid for 1 hour followed by 90 days cold stratification. Also, Rehman and Park (2000) observed that cold stratification for 60 days increased germination of manually scarified seeds. According to Rudolf (1974a), seeds of M. aquifolium require cold stratification for germination, whereas, Dirr and Heuser (1987) state that the embryo of $M$. aquifolium seeds is possibly immature or improperly developed and, for the maximum germination, a warm followed by cold stratification is required. It is also worth noting that growth regulators, such as gibberellic acid, are used to partially or fully replace the period of cold stratification required to break physiological dormancy in the seeds of many plant species (Baskin and Baskin 1998).

The present study aims to evaluate the effect of scarification with sulphuric acid, cold stratification and gibberellic acid $\left(\mathrm{GA}_{3}\right)$ treatments (and their combinations) on dormancy breaking of $K$. paniculata and $M$. aquifolium seeds and to enable the understanding of the nature of seed dormancy exhibited by each of the species.

\section{Materials and Methods}

Mature fruits of $K$. paniculata and M. aquifolium were collected from plants growing in parks in Thessaloniki, northern Greece, during the autumn 2010. After collection, the seeds were extracted manually from the fruits. Subsequently, sieving and flotation were used to clean the seeds and to remove non-filled seeds. The clean filled seeds were dried under laboratory conditions and were stored in sealed containers at $3-5^{\circ} \mathrm{C}$ until the beginning of the experiments.

\section{Seed treatment}

Germination experiments started in January 2011 and were conducted in the laboratory of Silviculture, Department of Forestry and Natural Environment, Aristotle University of Thessaloniki.

\section{Koelreuteria paniculata}

Seeds of $K$. paniculata were immersed in concentrated (95-97\%) sulphuric acid and gently stirred periodically (acid scarification, AS). The duration of immersions in acid was 0,30 and 60 minutes. After treatment the seeds were removed from the acid and were washed thoroughly under running water. The seeds of each treatment with sulphuric acid $(0$, 30 and 60 minutes) were randomly divided in three groups. Each group of seeds of each treatment with sulphuric acid was soaked in each one of three gibberellic acid $\left(\mathrm{GA}_{3}\right)$ concentrations $(0,500$ and 1000 $\mathrm{mg} \mathrm{l}^{-1}$ ) for 24 hours, and then placed in plastic containers with moist sterilized river sand and was subjected to cold stratification (CS) for 0, 1, 2 and 3 months. The CS of seeds took place in a refriger- 
ator at temperatures fluctuating between 3 and $5^{\circ} \mathrm{C}$. There were nine plastic containers corresponding to the nine combinations between duration of AS $(0,30$ and 60 minutes) and concentrations of $\mathrm{GA}_{3}(0,500$ and $1000 \mathrm{mg} \mathrm{l}^{-1}$ ). Totally, 36 treatments (combinations between AS, $\mathrm{GA}_{3}$ and CS) were applied.

\section{Mahonia aquifolium \\ Seeds of M. aquifolium were soaked in 0, 500, 1000 or $2000 \mathrm{mg} \mathrm{l}^{-1} \mathrm{GA}_{3}$ for 24 hours, and then placed in plastic containers with moist sterilized river sand. Subsequently, they were subjected to CS for $0,1,2,3$ or 4 months. The CS of seeds took place in a refriger- ator at temperatures fluctuating between 3 and $5^{\circ} \mathrm{C}$. There were four plastic containers corresponding to the four concentrations of $\mathrm{GA}_{3}$. Totally, 20 treatments (combinations between $\mathrm{GA}_{3}$ and $\mathrm{CS}$ ) were applied.}

\section{Germination test}

For K. paniculata and M. aquifolium species, a random sample of 120 seeds was taken out from each plastic container at the end of each stratification period and randomly placed in 4 plastic petri dishes (90 $\mathrm{mm}$ in diameter: 30 seeds per petri dish). In both species, for each treatment there were 4 replications of 30 seeds. Sterilized river sand moistened with distilled water was used as substrate in petri dishes. Prior to the arrangement of seeds in petri dishes, the seeds were dusted with fungicide to prevent fungi development. The petri dishes were randomly arranged on shelves in the growth chamber. The temperature in the growth chamber was set at $20^{\circ} \mathrm{C}$ for a 16 -hour dark period and $25^{\circ} \mathrm{C}$ for an 8-hour light period.

For each species, the germination test lasted 8 weeks and the germinated seeds were counted each week. Seed germination was determined by the appearance of a radicle at least $2 \mathrm{~mm}$ long (I.S.T.A. 1999). Finally, for each treatment of each species the germination percentage (GP) were calculated as the average of the 4 replications.

\section{Statistical analysis}

For each species a completely randomised experimental design was used. For K. paniculata, a CS period longer than 2 months was not used for the seeds which were acid-scarified for 30 minutes as, at the end of the 2-month period of CS, germinated seeds appeared. Similarly, for the seeds scarified for 60 minutes, a CS period longer than one month was not used. It is worth noting that, as regards M. aquifolium, treatment combinations (between $\mathrm{GA}_{3}$ and $\mathrm{CS}$ ), during which seeds did not germinate were not included in the statistical analysis. The germination percentage data of $K$. paniculata and M. aquifolium were arc-sine square root transformed before the analysis
(Snedecor and Cochran 1980). The transformed data were checked for normality and homogeneity of variances and then analysed by one-way ANOVA. Comparisons of the means were made using the Duncan test (Klockars and Sax 1986). All statistical analyses were carried out using SPSS (SPSS, Inc., USA).

\section{Results}

\section{Koelreuteria paniculata}

There were significant differences in GPs $(\alpha=$ 0.05) among the combinations of AS durations, $\mathrm{GA}_{3}$ concentrations and CS periods $\left[\mathrm{F}_{(26,81)}=122.36, \mathrm{p}=\right.$ 0.000].

In all $\mathrm{GA}_{3}$ treatments $\left(0,500\right.$ and $\left.1000 \mathrm{mg} \mathrm{l}^{-1}\right)$ of the un-scarified seeds and the seeds scarified for 30 and 60 minutes, the cold-stratified seeds exhibited higher GPs than the seeds which were not stratified (Table 1). In treatments with 500 and $1000 \mathrm{mg} \mathrm{l}^{-1}$ $\mathrm{GA}_{3}$ of unscarified seeds, GP significantly increased ( $\mathrm{p}<0.05$ ) by increasing the CS period. However, in the intact seeds, which were not treated with $\mathrm{GA}_{3}$, there was not a significant difference $(p>0.05)$ in GP between the seeds stratified for 2 months and those stratified for 3 months. In each treatment with $\mathrm{GA}_{3}\left(0,500\right.$ and $\left.1000 \mathrm{mg} \mathrm{l}^{-1}\right)$ of seeds scarified for 30 minutes there was not a significant difference ( $\mathrm{p}$ $>0.05$ ) in GP for the seeds stratified for 1 month and those stratified for 2 months. Furthermore, for each CS period (0, 1, 2 and 3 months) there was no difference $(p>0.05)$ in the GPs of the intact seeds among the $\mathrm{GA}_{3}$ concentrations $(0,500$ and $1000 \mathrm{mg}$ $\left.\mathrm{l}^{-1}\right)$. In contrast, concerning the seeds scarified for 30 and 60 minutes, which were not stratified, $\mathrm{GA}_{3}$ application significantly increased GP $(p<0.05)$. Only the seeds that were not stratified after AS treatment for 60 minutes demonstrated a significant increase in GP $(p<0.05)$ when $\mathrm{GA}_{3}$ concentration was also increased. As regards the 1-month stratified seeds, in each $\mathrm{GA}_{3}$ concentration, the increase of AS duration significantly increased $(p<0.05)$ seed germination. It is also worth noting that the highest GPs ( $\mathrm{p}<$ 0.05 ), regardless of $\mathrm{GA}_{3}$ application, were yielded in seeds scarified for 60 minutes and then cold stratified for a one-month period. Furthermore, in each $\mathrm{GA}_{3}$ treatment, the seeds scarified for 30 minutes and then stratified for 2 months exhibited higher GPs ( $p$ $<0.05$ ) than the unscarified seeds subjected to the same period of CS.

\section{Mahonia aquifolium}

There were significant differences in GPs $(\alpha=$ 0.05) among the combinations of $\mathrm{GA}_{3}$ concentrations and CS periods $\left[\mathrm{F}_{(7,24)}=109.31, \mathrm{p}=0.000\right]$. 
Table 1. Germination percentages of $K$. peniculata seeds after various combinations of acid scarification, $\mathrm{GA}_{3}$ and cold stratification treatments

\begin{tabular}{|c|c|c|c|}
\hline Acid Scarification (minutes) & $\mathrm{GA}_{3}\left(\mathrm{mg} \mathrm{l}^{-1}\right)$ & Cold Stratification (months) & Germination percentage (\%, S.E.) \\
\hline \multirow[t]{12}{*}{ 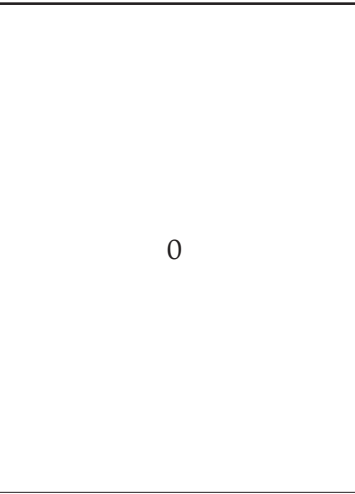 } & \multirow{4}{*}{0} & 0 & $0.83 \mathrm{i}^{1} \quad 0.83$ \\
\hline & & 1 & $10.83 \mathrm{~h} 1.59$ \\
\hline & & 2 & $34.17 \mathrm{fg} 2.84$ \\
\hline & & 3 & 44.17 def 2.84 \\
\hline & \multirow{4}{*}{500} & 0 & 0.83 i 0.83 \\
\hline & & 1 & 14.1 h 3.15 \\
\hline & & 2 & 30.00 g 2.72 \\
\hline & & 3 & 41.67 ef 2.89 \\
\hline & \multirow{4}{*}{1000} & 0 & 0.83 i 0.83 \\
\hline & & 1 & $15.00 \mathrm{~h} 1.67$ \\
\hline & & 2 & $36.66 \mathrm{fg} 3.04$ \\
\hline & & 3 & 50.00 de 3.04 \\
\hline \multirow{12}{*}{30} & \multirow{4}{*}{0} & 0 & $0.00 \mathrm{i}$ \\
\hline & & 1 & 75.83 bc 2.84 \\
\hline & & 2 & 80.83 b 2.85 \\
\hline & & 3 & -2 \\
\hline & \multirow{4}{*}{500} & 0 & 10.00 h 2.36 \\
\hline & & 1 & $73.33 \mathrm{bc} 3.04$ \\
\hline & & 2 & 76.67 bc 3.04 \\
\hline & & 3 & - \\
\hline & \multirow{4}{*}{1000} & 0 & 11.67 h 2.15 \\
\hline & & 1 & 67.50 c 3.44 \\
\hline & & 2 & $73.33 \mathrm{bc} 1.36$ \\
\hline & & 3 & - \\
\hline \multirow{12}{*}{60} & \multirow{4}{*}{0} & 0 & 1.66 i 0.96 \\
\hline & & 1 & 92.50 a 2.10 \\
\hline & & 2 & - \\
\hline & & 3 & - \\
\hline & \multirow{4}{*}{500} & 0 & $32.50 \mathrm{fg} 2.50$ \\
\hline & & 1 & 94.17 a 2.84 \\
\hline & & 2 & - \\
\hline & & 3 & - \\
\hline & \multirow{4}{*}{1000} & 0 & $55.00 \mathrm{~d} 2.15$ \\
\hline & & 1 & 95.83 a 2.10 \\
\hline & & 2 & - \\
\hline & & 3 & - \\
\hline
\end{tabular}

\footnotetext{
${ }^{1}$ Means are statistically different at $\mathrm{p}<0.05$, when they share no common letter. The comparisons were made using Duncan test.

${ }^{2}$ For the seeds which were acid-scarified for 30 minutes, a 3-month CS period of seeds was not used as at the end of the 2-month CS period germinated seeds appeared in the refrigerator. Similarly, for the seeds scarified for 60 minutes, a CS period longer than one month was not used.
}

None of the $M$. aquifolium seeds, regardless of GA application, subjected to CS for 1 and 2 months, germinated. In all $\mathrm{GA}_{3}$ treatments, an increase in the CS period from 3 to 4 months significantly increased $(p<0.05)$ the germination of seeds (Table 2). Furthermore, in each CS period (3 and 4 months) the seeds treated with $\mathrm{GA}_{3}$ (500, 1000 and $\left.2000 \mathrm{mg} \mathrm{l}^{-1}\right)$ exhibited higher $(\mathrm{p}<0.05)$ GPs than those not treated with $\mathrm{GA}_{3}\left(0 \mathrm{mg} \mathrm{l}^{-1}\right)$ except for one case. After a 4-month period of CS, untreated and seeds treated with $500 \mathrm{mg} \mathrm{l}^{-1}$ of $\mathrm{GA}_{3}$ exhibited GPs with no significant difference $(\mathrm{p}>0.05)$. However, in each period of CS (3 and 4 months) the increase in concentration of $\mathrm{GA}_{3}\left(500,1000\right.$ and $\left.2000 \mathrm{mg} \mathrm{l}^{-1}\right)$ did not affect $(p>0.05)$ seed germination significantly.

\section{Discussion}

As far as K. paniculata species is concerned, previous studies have shown that its seeds exhibit exogenous and endogenous dormancy (Rehman and Park 2000; Michler and Rudolf 2008) and need a combination of treatments before sowing in order to germinate (Rudolf 1974b; Rehman and Park 2000). Our results are congruent with the previous statement since seed dormancy was not overcome with a 
Table 2. Germination percentages of $M$. aquifolium seeds after various combinations of $\mathrm{GA}_{3}$ and cold stratification treatments

\begin{tabular}{ccc}
\hline $\mathrm{GA}_{3}\left(\mathrm{mg}^{\left.1^{-1}\right)}\right.$ & $\begin{array}{c}\text { Cold Stratification } \\
\text { (months) }\end{array}$ & $\begin{array}{c}\text { Germination percentage } \\
(\%, \text { S.E. })\end{array}$ \\
\hline \multirow{3}{*}{0} & 0 & 0.00 \\
& 1 & 0.00 \\
500 & 2 & 0.00 \\
& 3 & $5.83 \mathrm{~d}^{1} 1.60$ \\
& 4 & $57.50 \mathrm{~b} 2.84$ \\
\hline \multirow{5}{*}{1000} & 0 & 0.00 \\
& 1 & 0.00 \\
& 2 & 0.00 \\
& 3 & $10.83 \mathrm{c} 2.10$ \\
& 4 & $65.00 \mathrm{ab} 3.19$ \\
\hline \multirow{5}{*}{2000} & 0 & 0.00 \\
& 1 & 0.00 \\
& 2 & 0.00 \\
& 3 & $14.17 \mathrm{c} 1.60$ \\
& 4 & $68.33 \mathrm{a} 3.47$ \\
\hline & 0 & 0.00 \\
& 1 & 0.00 \\
& 2 & 0.00 \\
& 3 & $11.67 \mathrm{c} 2.15$ \\
& 4 & $70.84 \mathrm{a} 2.85$ \\
\hline
\end{tabular}

${ }^{1}$ Means are statistically different at $\mathrm{p}<0.05$, when they share no common letter. The comparisons were made using Duncan test.

single AS treatment (up to 60 minutes). The specific result provides sound evidence that $K$. paniculata seeds exhibit physiological dormancy. Although AS degraded seed coat, the seeds did not germinate due to embryo dormancy, which corroborates the conclusions drawn by Rehman and Park (2000), who stated that seeds subjected only to manual scarification (the seeds were pierced by a needle at the end of cotyledon) are unable to germinate. In contrast, as reported by Stilinovic and Grbic (1988), a single mechanical scarification treatment improved the $K$. paniculata seed germination (61\%), although germination was significantly increased by acid or mechanical scarification followed by cold moist stratification treatment. Concerning the effect of scarification treatment on seed germination, the results of the research made by Rehman and Park (2000) and also of the present study contradict Stilinovic and Grbic's (1988) research possibly due to the conditions of seed storage. In Rehman and Park's (2000) research and also in the present study, $K$. paniculata seeds were dry stored in a sealed container at $3-5^{\circ} \mathrm{C}$ until the beginning of the experiments, whereas storage length and seed conditions are unknown in Stilinovic and Grbic's (1988) research, in which the possibility of dry storage at room temperature may explain the different results. According to Baskin and Baskin (1998), a period of dry storage at room temperature replaces or reduces the length of the CS period required to break dormancy in seeds with nondeep and intermediate physiological dormancy. Furthermore, in the present study, the intact seeds, which were only cold stratified (up to 3 months) exhibited low germination percentages $(0.83-44.17 \%$, Table 1). Despite the fact that embryo dormancy was broken by CS treatment and growth potential of embryo increased, the embryo force did not overcome the inhibiting effects of the seed coat. These results confirm that, apart from physiological dormancy, the seed coat also inhibits the germination of $K$. paniculata seeds. The results of the present research demonstrated that the combination of AS and CS treatments was necessary to break dormancy and maximize the germination of $K$. paniculata seeds. In 1-month stratified seeds, a 60-minute AS treatment prior to CS (in all GA $\mathrm{G}_{3}$ treatments $-0,500$ and 1000 $\mathrm{mg}^{-1}$ ) yielded the highest GPs, which implies that a 60-minute AS duration of seeds overcame entirely seed coat dormancy and an 1-month period of CS was enough to break embryo dormancy. Potentially, in a 30-minute duration of AS, the embryo dormancy was overcome after an 1-month period of CS, but the seed coat was still hard and provided resistance to radicle emergence. Furthermore, for the same AS duration, the penetration resistance of seed coat was not reduced by increasing the CS period from 1 to 2 months as germination was not significantly improved by increasing the CS period. According to Stilinovic and Grbic (1988), a 2-month CS period is needed to maximize germination $(88.50 \%)$ of seeds scarified with sulfuric acid for 60 minutes. Similarly, Ertekin (2011) found that a 2-month CS period of seeds that have been firstly soaked for 5 days in distilled water at $40^{\circ} \mathrm{C}$ is needed to maximize germination $(90 \%)$ of $K$. paniculata seeds. The fact that the germination of intact seeds treated with $\mathrm{GA}_{3}$ and then cold stratified (for 0, 1, 2 or 3 months) was as high as the germination of intact seeds that were only cold stratified for the same period, whereas the scarified seeds (for 30 or 60 minutes) which were treated with $\mathrm{GA}_{3}$ prior to CS exhibited significantly higher germination than un-scarified seeds treated with $\mathrm{GA}_{3}$ and then cold stratified for the same period, which implies that the $K$. paniculata seeds may have an impermeable seed coat and AS treatment erode seed coat making it permeable to $\mathrm{GA}_{3}$. $\mathrm{GA}_{3}$ application improved only the germination of scarified seeds which were not stratified. Exogenous $\mathrm{GA}_{3}$ application may increase the growth potential of embryo; however, it did not manage to break entirely seed coat resistance of an adequate percentage of seeds. According to Baskin and Baskin (1971) and Rascio et al. (1998), pretreatment of Ruellia humilis and Cercis siliquastrum seeds with $\mathrm{GA}_{3}$ results in an increase in the growth potential of the embryo. Rehman and Park (2000) found that application of 100, 200 and $300 \mathrm{mg} \mathrm{l}^{-1} \mathrm{GA}_{3}$, increased germination of 
manually scarified seeds of $K$. paniculata from 0 (control) to 17,18 and $15 \%$ respectively.

Prolonged cold stratification is essential for the germination of $M$. aquifolium seeds since seeds stratified for 1 or even 2 months did not germinate at all, while 4 months of cold stratification alone yielded germination percentages equal to $57.5 \%$. A CS period longer than 4 months was not used, because towards the end of the 4-month CS period germinated seeds appeared. Previous studies on seeds of Mahonia species suggest that they exhibit dormancy and that stratification is required to overcome it. According to Baskin et al. (1993), a 10-week period of CS is required to break completely the physiological dormancy in $M$. fremontii seeds. Similarly, seeds of $M$. bealei and $M$. japonica germinate well when they are firstly subjected to CS for 1 to 2 months (Dirr and Heuser 1987). In contrast, M. aquifolium seeds may have immature or improperly developed embryo and 4 months warm stratification followed by 4 months of CS are required for maximum germination (Dirr and Heuser 1987). Furthermore, Neugebauer (1980) reported that $M$. aquifolium seeds require stratification in order to germinate and maximum germination is obtained after a 4-month period of seeds after-ripening in a moist atmosphere at $20^{\circ} \mathrm{C}$ followed by 4 months of chilling at $2-5^{\circ} \mathrm{C}$. It is possibly, if seeds in the present study were subjected to warm stratification prior to CS, germination would have been even higher. In almost all cases, the percentage of M. aquifolium seeds germinated was higher with $\mathrm{GA}_{3}$ treatment prior to CS than with CS only. $\mathrm{GA}_{3}$ treatment may substitute the warm stratification requirement for germination in seeds. Hidayati et al (2000) found that as regards the seeds of Sambucus canadensis and of Sambucus pubens which require warm stratification followed by CS for germination, $\mathrm{GA}_{3}$ substitutes warm stratification rather than CS. Furthermore, in Carpinus betulus seeds, $\mathrm{GA}_{3}$ application appeared to replace entirely the requirements for the warm stratification, to shorten the period of CS requirement and to promote germination (Pipinis et al. 2012).

\section{Conclusions}

In conclusion, the dormancy of $K$. paniculata seeds is successfully overcome with sulphuric acid scarification followed by cold stratification. In the case of $M$. aquifolium, prolonged cold stratification is essential for the seed germination and $\mathrm{GA}_{3}$ (1000 or 2000 $\mathrm{mg} \mathrm{l}^{-1}$ ) application followed by cold stratification is more effective at promoting germination than cold stratification only. Thus, a 60-minute scarification with sulfuric acid followed by an 1-month CS period is recommended as an effective treatment which maximizes germination of $K$. paniculata seeds, where- as $\mathrm{GA}_{3}$ (1000 or $2000 \mathrm{mg} \mathrm{l}^{-1}$ ) treatment for 24 hours followed by a 4-month CS period enhances germination of $M$. aquifolium seeds. The results of the present study on seed dormancy and germination are of practical interest in the nursery industry as they can be applied to improve the method of propagation of the above species with seeds.

\section{References}

Baskin J.M., Baskin C.C. 1971. Effect of chilling and gibberellic acid on growth potential of excised embryos of Ruellia humilis. Planta 100: 365-369.

Baskin C.C., Baskin J.M. 1998. Seeds - ecology, biogeography, and evolution of dormancy and germination. Academic Press, San Diego.

Baskin J.M., Baskin C.C. 2004. A classification system for seed dormancy. Seed Science Research 14: $1-16$.

Baskin C.C., Baskin J.M., Meyer S.E. 1993. Seed dormancy in the Colorado Plateau shrub Mahonia fremontii (Berberidaceae) and its ecological and evolutionary implications. The Southwestern Naturalist 38: 91-99.

Dirr M.A., Heuser C.W.J. 1987. The reference manual of woody plant propagation: from seed to tissue culture. Varsity Press Inc., Athens, Georgia.

Ertekin M. 2011. Effects of microorganisms, hormone treatment and stratification on seed germination of Goldenrain Tree (Koelreuteria paniculata). International Journal of Agriculture and Biology 13: $38-42$.

Gunduz K. 2013. Morphological and phytochemical properties of Mahonia aquifolium from Turkey. Pakistan Journal of Agricultural Sciences 50: 439-443.

Hidayati S.N., Baskin J.M., Baskin C.C. 2000. Morphophysiological dormancy in seeds of two North American and one Eurasian species of Sambucus (Caprifoliaceae) with underdeveloped spatulate embryos. American Journal of Botany 87: 16691678.

International Seed Testing Association (I.S.T.A.) 1999. International rules for seed testing. Seed Science and Technology 27, Supplement.

Klockars A., Sax G. 1986. Multiple Comparisons. Sage Publications, Newbury Park, California.

Kowarik I. 1992 Einfuhrung und Ausbreitung nichteinheimischer Geholzarten in Berlin und Brandenburg und ihre Folgen fur Flora und Vegetation: ein Modell fur die Freisetzung gentechnisch veranderter Organismen. Botanischer Vereine von Berlin und Brandenburg 3: 1-188.

Macdonald B. 2006. Practical woody plant propagation for nursery growers. Timber Press, Inc. Portland, Oregon. 
Mackay A.C., Mcgill C.R., Fountain D.W., Southward R.C. 2002. Seed dormancy and germination of a panel of New Zealand plants suitable for re-vegetation. New Zealand Journal of Botany 40: $373-$ 382.

Michler C.H., Rudolf P.O. 2008. Koelreuteria paniculata Laxm. panicled golden raintree. In: Woody plant seed manual. Bonner F.T., Karrfalt R.P. (eds.). Agriculture Handbook No. 727, U.S. Department of Agriculture, Forest Service, pp. 624-625.

Neugebauer K.H. 1980. Propagation of Mahonia aquifolium from seed. Deutsche Baumschule 32: 8285.

Nikolaeva M.G. 1977. Factors controlling the seed dormancy pattern. In: The Physiology and Biochemistry of Seed Dormancy and Germination. Khan A.A. (ed.). North-Holland, Amsterdam, pp. 51-74.

Pipinis E., Milios E., Kiamos N., Mavrokordopoulou O., Smiris P. 2012. Effects of stratification and pre-treatment with gibberellic acid on seed germination of two Carpinus species. Seed Science and Technology 40: 21-31.

Rascio N., Mariani P., Vecchia F.D., Rocca N.L., Profumo P., Gastaldo P. 1998. Effects of seed chilling or $\mathrm{GA}_{3}$ supply on dormancy breaking and plantlet growth in Cercis siliquastrum L. Plant Growth Regulation 25: 53-61.

Rehman S., Park I.H. 2000. Effect of scarification, GA and chilling on the germination of goldenrain-tree (Koelreuteria paniculata Laxm.) seeds. Scientia Horticulturae 85: 319-324.

Rudolf P.O. 1974a. Berberis L. barberry, mahonia. In: Seeds of Woody Plants in the United States. Schopmeyer C.S. (ed.). Agriculture Handbook No. 450, U.S. Department of Agriculture, Forest Service, Washington D.C., pp. 247-251.

Rudolf P.O. 1974b. Koelreuteria paniculata Laxm. panicled golden raintree. In: Seeds of Woody Plants in the United States. Schopmeyer C.S. (ed.). Agriculture Handbook No. 450, U.S. Department of Agriculture, Forest Service, Washington D.C., pp. 474-475.

Snedecor G.W., Cochran W.G. 1980. Statistical Methods. 7th Ed. The Iowa State University Press. Ames, Iowa.

Stilinovic S., Grbic M. 1988. Effect of various presowing treatments on the germination of some woody ornamental seeds. Acta Horticulture 226: 239445. 